Original Research Article

\title{
Study of evaluation of hepatoprotective potential of lycopene in rat models of paracetamol and antitubercular drugs (isoniazid + rifampicin) induced hepatotoxicity
}

\author{
Shirish Shashikant Joshi, Firoz Mubarak Tadavi*, Manjunatha T. A., \\ Dnyaneshwar Gurunath Kurle
}

Department of Pharmacology and Therapeutics, Seth G. S. Medical College and K. E. M. Hospital, Mumbai, Maharashtra, India

Received: 18 May 2017 Accepted: 17 June 2017

*Correspondence to:

Dr. Firoz Mubarak Tadavi, Email: drfiroztadavi@ gmail.com

Copyright: (c) the author(s), publisher and licensee Medip Academy. This is an openaccess article distributed under the terms of the Creative Commons Attribution NonCommercial License, which permits unrestricted noncommercial use, distribution, and reproduction in any medium, provided the original work is properly cited.

\begin{abstract}
Background: The exact role of lycopene has not been studied in the past for its hepatoprotective effects. Hence it was decided to explore its anti-oxidant and anti-inflammatory properties in acute and chronic models of drug- induced hepatotoxicity with the aim to evaluate hepatoprotective potential in rat models of paracetamol and antitubercular drugs (isoniazid + rifampicin) induced hepatotoxicity.

Methods: The study was carried out in 70 Wistar rats in two phases. In phase I, models of paracetamol and anti-tubercular drugs induced hepatotoxicity were standardized in 22 Wistar rats and in phase II, hepatoprotective potential of lycopene was evaluated in paracetamol and anti-tubercular drugs induced hepatic damage using 48 Wistar rats. The effects of lycopene were compared with silymarin.
\end{abstract}

Results: There was a significant $(\mathrm{p}<0.05)$ reduction in serum bilirubin levels with silymarin and lycopene $10 \mathrm{mg} / \mathrm{kg}$ treated groups signifying protection against hepatic damage, while vehicle control and lycopene $5 \mathrm{mg} / \mathrm{kg}$ treated groups had high bilirubin values. Similarly, significant $(\mathrm{p}<0.001)$ reduction in the levels of serum transaminases were observed with all the treatment groups though more evident in the positive control and lycopene $10 \mathrm{mg} / \mathrm{kg}$ treated groups.

Conclusions: The results of the present study prove that lycopene exerts hepatoprotective effect against paracetamol and anti-tubercular drugs induced hepatic damage in rats. Lycopene needs to be evaluated in other models of hepatotoxicity and further studies are required to delineate its mechanism of action. Lycopene could be a potential hepatoprotective for clinical use in future.

Keywords: Anti-oxidant, Anti-inflammatory, Liver injury, Serum bilirubin, Silymarin

\section{INTRODUCTION}

Drug induced hepatotoxicity is a ubiquitous clinical scenario. It has a significant impact on health due to associated high morbidity and mortality. Drug induced hepatotoxicity is responsible for $5 \%$ of overall hospital admissions and up to $50 \%$ of all acute liver failures. ${ }^{1}$ It accounts for as many as $10 \%$ of hepatitis cases in adults overall, for about $40 \%$ of hepatitis cases in adults over 50 years old and over $25 \%$ cases of fulminant hepatic failure. $^{2}$
Paracetamol represents the most common cause of all drug induced acute liver failures and accounts for $25-40 \%$ cases of fulminant hepatic failure in Western countries (Indian data lacking). ${ }^{2}$ Other common drugs implicated in drug induced hepatotoxicity include NSAIDs, statins, anti-hypertensives, halothane, antiretroviral drugs and anti-cancer drugs. The spectrum of drug induced hepatotoxicity includes various clinical and pathological expressions of liver damage consisting of metabolic derangements, cytotoxic injury, cholestatic injury, mixed cytotoxic and cholestatic injury, steatosis, cirrhosis, 
phospholipidosis, neoplastic lesions, vascular lesions, acute and chronic hepatitis. ${ }^{3}$

The exact role of lycopene has not been studied in the past for its hepatoprotective effects. Hence it was decided to explore its anti-oxidant and anti-inflammatory properties in acute and chronic models of drug- induced hepatotoxicity. These two drugs being the most commonly implicated hepatotoxic drugs in clinical scenario. Hence, it was decided to evaluate the role of lycopene as a hepatoprotective in experimental models of paracetamol and anti-tubercular drug (isoniazid + rifampicin) induced hepatotoxicity, using silymarin as a positive control.

\section{METHODS}

This experimental study was carried out in two phases. In phase I, models of paracetamol and anti-tubercular drugs induced hepatotoxicity were standardized in Wistar rats and in phase II, hepatoprotective potential of lycopene was evaluated in paracetamol and anti-tubercular drugs induced hepatic damage. The effects of lycopene were compared with silymarin, a proven hepatoprotective agent in both these models of hepatotoxicity.

The study was conducted in strict accordance with the study protocol and CPCSEA guidelines. Study animals were housed in the Central Animal House of our Institute, in an air-conditioned area with 12-15 filtered fresh air changes, temperature $22 \pm 3^{\circ} \mathrm{C}$, relative humidity $30-70 \%$. Four rats per cage were housed in polypropylene cages having husk paddy as the bedding, during the study. Twelve hourly light and dark cycles were maintained.

The model was standardized and hepatic damage was confirmed in both the models. The effects of lycopene were evaluated in experimental models of paracetamol and anti-tubercular drug induced hepatic damage. 48 Wistar rats of either sex weighing between 180-200 grams were used for the entire study. Lycopene was used in two doses of $5 \mathrm{mg} / \mathrm{kg}$ and $10 \mathrm{mg} / \mathrm{kg}$ based on the dose in previous animal studies of lycopene as hepatoprotective. Lycopene was administered orally, daily, suspended in $0.5 \% \mathrm{CMC}^{4}$ Silymarin was administered in the dose of $50 \mathrm{mg} / \mathrm{kg}$, orally, suspended in $0.5 \% \mathrm{CMC}$, daily for the study duration. ${ }^{5}$

In Part A, the effects of lycopene were evaluated in paracetamol induced hepatic damage, using silymarin as positive control. 24 Wistar rats were randomly allocated into four groups namely vehicle control (0.5\% CMC), silymarin $(50 \mathrm{mg} / \mathrm{kg})$, lycopene $(5 \mathrm{mg} / \mathrm{kg})$ and lycopene $(10 \mathrm{mg} / \mathrm{kg})$, each group containing 6 rats. The study drugs were administered for a duration of 7 days. On the $8^{\text {th }}$ day, induction of hepatic damage was carried out with paracetamol given orally in the single dose of $2 \mathrm{~g} / \mathrm{kg}$. The body weight of the study animals was recorded. 24 hours following the administration of paracetamol, $2 \mathrm{ml}$ of blood was collected by puncturing the retro-orbital sinus and blood was sent for biochemical investigations. Then the rats were euthanized by administering ketamine intraperitoneally. The liver was dissected out, washed in cold saline and blotted dry by placing it on tissue paper. Weight and volume of liver was measured and processed further for histopathological examination.

In Part B, the effects of lycopene were evaluated in Isoniazid $50 \mathrm{mg} / \mathrm{kg}+$ Rifampicin $50 \mathrm{mg} / \mathrm{kg}$ induced hepatic damage, using silymarin as positive control. 24 Wistar rats were randomly allocated into four groups namely vehicle control $(0.5 \% \quad \mathrm{CMC})$, silymarin $(50 \mathrm{mg} / \mathrm{kg})$, lycopene $(5 \mathrm{mg} / \mathrm{kg})$ and lycopene $(10 \mathrm{mg} / \mathrm{kg})$, each group containing 6 rats. The study drugs were administered for a duration of 14 days. On the $15^{\text {th }}$ day, induction of hepatic damage was carried out with Isoniazid $50 \mathrm{mg} / \mathrm{kg}+$ Rifampicin $50 \mathrm{mg} / \mathrm{kg}$ given intraperitoneally daily for 14 days.

On Day 15, body weight of the study animals was recorded. $2 \mathrm{ml}$ of blood was collected by puncturing the retro-orbital sinus and blood was sent for biochemical investigations. Then the rats were euthanized and dissection of rat liver was carried out. Weight and volume of liver were measured and histopathological examination of the liver was carried out.

\section{Statistical analysis}

Statistical analysis was done using MS Excel 2013 and GraphPad Instat 3.0. Parametric data in different treatment groups were compared by using One way ANOVA and post hoc Tukey's test and on- Parametric data were compared using Kruskal-Wallis test and post hoc Dunn's test.

A 'p' value <0.05 was considered to be statistically significant.

\section{RESULTS}

\section{Part A}

\section{Morphological parameters}

Table 1: Effect of study drugs on liver weight and volume in rat model of paracetamol induced hepatotoxicity.

\begin{tabular}{|lll|}
\hline Group (n=6) & $\begin{array}{l}\text { Liver weight } \\
\text { (mg/100gm } \\
\text { body weight) }\end{array}$ & $\begin{array}{l}\text { Liver volume } \\
\text { (ml/100gm } \\
\text { body weight) }\end{array}$ \\
\hline Vehicle control & $4.79 \pm 0.36$ & $4.65 \pm 0.39$ \\
\hline Silymarin $50 \mathrm{mg} / \mathrm{kg}$ & $4.15 \pm 0.22^{*}$ & $3.90 \pm 0.24^{*}$ \\
\hline Lycopene $5 \mathrm{mg} / \mathrm{kg}$ & $4.68 \pm 0.43$ & $4.55 \pm 0.41$ \\
\hline Lycopene $10 \mathrm{mg} / \mathrm{kg}$ & $4.13 \pm 0.22^{*}$ & $3.90 \pm 0.18^{*}$ \\
\hline
\end{tabular}

All values represent Mean \pm SD. $* \mathrm{p}<0.05, * * \mathrm{p}<0.001$ using one way ANOVA with post hoc Tukey's test (versus vehicle control). 
There were no macroscopic changes observed in the liver in any of the study groups. There was statistically significant decrease in the liver weight and volume observed with groups that received silymarin $50 \mathrm{mg} / \mathrm{kg}$ and lycopene $10 \mathrm{mg} / \mathrm{kg}$ when compared with vehicle control (Table 1).

\section{Biochemical parameters}

There was a significant $(\mathrm{p}<0.05)$ reduction in serum bilirubin levels with silymarin and lycopene $10 \mathrm{mg} / \mathrm{kg}$ treated groups signifying protection against hepatic damage, while vehicle control and lycopene $5 \mathrm{mg} / \mathrm{kg}$ treated groups had high bilirubin values. Similarly significant $(p<0.001)$ reduction in the levels of serum transaminases were observed with positive control and lycopene 5 and $10 \mathrm{mg} / \mathrm{kg}$ treated groups (Table 2).

Table 2: Effect of study drugs on biochemical parameters in rat model of paracetamol induced hepatotoxicity.

\begin{tabular}{|llll|}
\hline $\begin{array}{l}\text { Group } \\
(\mathbf{n = 6})\end{array}$ & $\begin{array}{l}\text { Serum } \\
\text { bilirubin } \\
(\mathrm{mg} / \mathrm{dl})\end{array}$ & $\begin{array}{l}\text { Aspartate } \\
\text { transaminase } \\
(\mathrm{IU} / \mathrm{ml})\end{array}$ & $\begin{array}{l}\text { Alanine } \\
\text { transaminase } \\
(\mathrm{IU} / \mathrm{ml})\end{array}$ \\
\hline $\begin{array}{l}\text { Vehicle } \\
\text { control }\end{array}$ & $0.48 \pm 0.08$ & $211.43 \pm 31.16$ & $74.43 \pm 10.34$ \\
\hline $\begin{array}{l}\text { Silymarin } \\
50 \mathrm{mg} / \mathrm{kg}\end{array}$ & $0.22 \pm 0.04 *$ & $125.02 \pm 12.35 * *$ & $41.63 \pm 10.85 * *$ \\
\hline $\begin{array}{l}\text { Lycopene } \\
5 \mathrm{mg} / \mathrm{kg}\end{array}$ & $0.38 \pm 0.16$ & $137.58 \pm 14.67 * *$ & $47.72 \pm 5.28 * *$ \\
\hline $\begin{array}{l}\text { Lycopene } \\
10 \mathrm{mg} / \mathrm{kg}\end{array}$ & $0.21 \pm 0.05 *$ & $165.27 \pm 13.39 * *$ & $46.78 \pm 9.43 * *$ \\
\hline
\end{tabular}

All values represent Mean \pm SD. $*$ p $<0.05, * * p<0.001$ using one way ANOVA with post hoc Tukey's test (versus vehicle control)

\section{Histopathological changes}

Table 3: Effect of study drugs on histopathological parameters in rat model of paracetamol induced hepatotoxicity.

\begin{tabular}{|lllllllll|}
\hline $\begin{array}{l}\text { Group (n } \\
\text { =6) }\end{array}$ & \multicolumn{1}{c|}{ No. of Animals Showing } & $\begin{array}{l}\text { Composite } \\
\text { score } \\
\text { [median } \\
\text { (range) }\end{array}$ \\
\hline & $\mathbf{0}$ & I & II & III & 0 & I & II & \\
\hline $\begin{array}{l}\text { Vehicle } \\
\text { control }\end{array}$ & 0 & 3 & 3 & 0 & 1 & 5 & 0 & $6(2-7)$ \\
\hline $\begin{array}{l}\text { Silymarin } \\
50 \mathrm{mg} / \mathrm{kg}\end{array}$ & 1 & 5 & 0 & 0 & 5 & 1 & 0 & $1 *(0-6)$ \\
\hline $\begin{array}{l}\text { Lycopene } \\
5 \mathrm{mg} / \mathrm{kg}\end{array}$ & 0 & 3 & 3 & 0 & 1 & 5 & 0 & $6(2-7)$ \\
\hline $\begin{array}{l}\text { Lycopene } \\
10 \mathrm{mg} / \mathrm{kg}\end{array}$ & 1 & 4 & 1 & 0 & 5 & 1 & 0 & $1 * *(0-2)$ \\
\hline
\end{tabular}

${ }^{*} \mathrm{p}<0.01,{ }^{*} \mathrm{p}<0.001$ using Kruskal Wallis and post-hoc Dunn's test (versus vehicle control).

Scoring system by National Health Services, Maryland, USA, 1979.

Out of the six animals in the vehicle group three showed grade I degeneration while the remaining, three showed grade II degeneration. Five animals showed presence of 1-2 necrotic cells per high power field (Grade I) while one animal showed no necrosis. Similar changes were seen in the group that received lycopene in the dose of $5 \mathrm{mg} / \mathrm{kg}$ with regard to the number of animals. In the silymarin treated group, 5 animals showed no necrosis while one animal showed necrosis. Minimal degenerative changes were seen in 5 animals in the silymarin treated group. One animal showed no degeneration and grade II degeneration each, with remaining 4 animals showing grade I degeneration in the lycopene $10 \mathrm{mg} / \mathrm{kg}$ treated group. Only one animal in the lycopene $10 \mathrm{mg} / \mathrm{kg}$ treated group showed necrosis while 5 showed near normal hepatic parenchyma (Table 3, Figure 1).

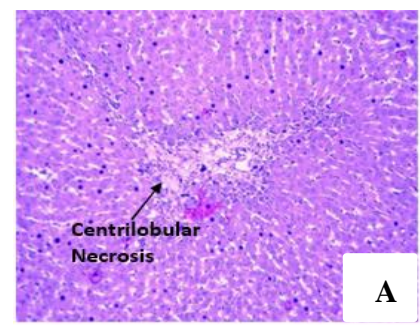

Vehicle control

Median composite score: 6(2-7)

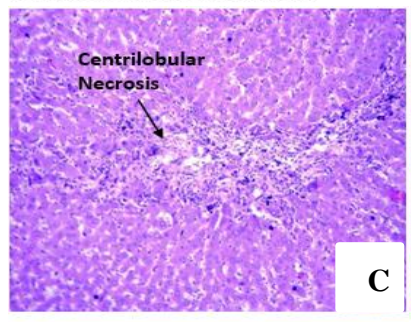

Lycopene $5 \mathrm{mg} / \mathrm{kg}$

Median composite score: $\mathbf{6 ( 2 - 7 )}$

Median composite score: $1^{* *}(0-2)$

Dunn's test (versus vehicle control)

(hematoxylin and eosin stain; magnification 10X10)

Figure 1: (A to D) effects of study drugs on histopathology in rat model of paracetamol induced hepatic damage (Part A).

\section{Part B}

\section{Morphological parameters}

There were no macroscopic changes observed in the liver in any of the study groups. There was trend towards decrease in the liver weight and volume observed with groups that received silymarin $50 \mathrm{mg} / \mathrm{kg}$ and lycopene 10 $\mathrm{mg} / \mathrm{kg}$ when compared with vehicle control however these changes were not statistically significant (Table 4).

\section{Biochemical parameters}

There was a significant $(\mathrm{p}<0.05)$ reduction in serum bilirubin levels with silymarin and lycopene $10 \mathrm{mg} / \mathrm{kg}$ treated groups signifying protection against hepatic 
damage, while vehicle control and lycopene $5 \mathrm{mg} / \mathrm{kg}$ treated groups had high bilirubin values. Similarly significant $(p<0.001)$ reduction in the levels of serum transaminases (aspartate and alanine transaminase) were observed with all the treatment groups; though more evident in the positive control and lycopene $10 \mathrm{mg} / \mathrm{kg}$ treated groups (Table 5).

Table 4: Effect of study drugs on liver weight and volume in rat model of anti- tubercular drug induced hepatotoxicity.

\begin{tabular}{|lll|}
\hline Group (n=6) & $\begin{array}{l}\text { Liver weight } \\
(\mathrm{mg} / 100 \mathrm{gm}) \\
\text { body weight }\end{array}$ & $\begin{array}{l}\text { Liver volume } \\
(\mathrm{ml} / 100 \text { 100 gm) } \\
\text { body weight) }\end{array}$ \\
\hline Vehicle control & $5.01 \pm 0.48$ & $4.80 \pm 0.48$ \\
\hline $\begin{array}{l}\text { Silymarin } \\
50 \mathrm{mg} / \mathrm{kg}\end{array}$ & $4.40 \pm 0.56$ & $4.25 \pm 0.56$ \\
\hline $\begin{array}{l}\text { Lycopene } \\
5 \mathrm{mg} / \mathrm{kg}\end{array}$ & $5.00 \pm 0.55$ & $4.67 \pm 0.47$ \\
\hline $\begin{array}{l}\text { Lycopene } \\
10 \mathrm{mg} / \mathrm{kg}\end{array}$ & $4.58 \pm 0.50$ & $4.43 \pm 0.48$ \\
\hline
\end{tabular}

All values represent Mean \pm SD

Table 5: Effect of study drugs on biochemical parameters in rat model of anti-tubercular drug induced hepatotoxicity.

\begin{tabular}{|llll|}
\hline $\begin{array}{l}\text { Group } \\
(\mathbf{n}=6)\end{array}$ & $\begin{array}{l}\text { Serum } \\
\text { bilirubin } \\
(\mathbf{m g} / \mathbf{d l})\end{array}$ & $\begin{array}{l}\text { Aspartate } \\
\text { transaminase } \\
(\text { IU/ml })\end{array}$ & $\begin{array}{l}\text { Alanine } \\
\text { transaminase } \\
(\mathbf{I U} / \mathrm{ml})\end{array}$ \\
\hline $\begin{array}{l}\text { Vehicle } \\
\text { control }\end{array}$ & $0.40 \pm 0.05$ & $186.03 \pm 13.71$ & $81.77 \pm 3.71$ \\
\hline $\begin{array}{l}\text { Silymarin } \\
50 \mathrm{mg} / \mathrm{kg}\end{array}$ & $0.28 \pm 0.08^{*}$ & $86.93 \pm 28.29 * *$ & $43.47 \pm 6.53^{* *}$ \\
\hline $\begin{array}{l}\text { Lycopene } \\
5 \mathrm{mg} / \mathrm{kg}\end{array}$ & $0.41 \pm 0.07$ & $141.37 \pm 13.01^{* *}$ & $46.83 \pm 5.56^{* *}$ \\
\hline $\begin{array}{l}\text { Lycopene } \\
10 \mathrm{mg} / \mathrm{kg}\end{array}$ & $0.33 \pm 0.03 *$ & $92.30 \pm 16.55^{* *}$ & $44.34 \pm 5.38^{* *}$ \\
\hline
\end{tabular}

All values represent Mean \pm SD. * $\mathrm{p}<0.05, * * \mathrm{p}<0.001$ using one way ANOVA with post hoc Tukey's test (versus vehicle control).

\section{Histopathological changes}

Out of the six animals in the vehicle group 4 showed grade I degeneration while the remaining two, showed grade II degeneration. Four animals showed presence of 1-2 necrotic cells per high power field (Grade I) while one animal showed 4-6 necrotic cells per high power field (Grade II). In the group that received lycopene in the dose of $5 \mathrm{mg} / \mathrm{kg}$, three animals showed grade I and grade II degeneration each. One animal in this group showed grade II necrosis while 4 showed grade I necrosis and one animal showed no necrotic cells.

Five animals out of six in the silymarin treated group showed normal liver cells in terms of no necrosis while only one animal showed presence of $<2$ necrotic cells per high power field. None of the animals in the lycopene 10 $\mathrm{mg} / \mathrm{kg}$ treated group showed necrosis while all the animals showed (4 showed Grade I and 2 showed Grade 2) degenerative changes (Table 6, Figure 2).

Table 6: Effect of study drugs on histopathological parameters in rat model of anti-tubercular drug induced hepatotoxicity.

\begin{tabular}{|c|c|c|c|c|c|c|c|c|}
\hline \multirow{3}{*}{$\begin{array}{l}\text { Group } \\
(n=6)\end{array}$} & \multicolumn{7}{|c|}{ No. of Animals Showing } & \multirow{2}{*}{$\begin{array}{l}\text { Composite } \\
\text { score } \\
\text { [median } \\
\text { (range)] }\end{array}$} \\
\hline & \multicolumn{4}{|c|}{ Degeneration } & \multicolumn{3}{|c|}{ Necrosis } & \\
\hline & $\mathbf{0}$ & I & II & III & $\mathbf{0}$ & $\mathbf{I}$ & II & \\
\hline $\begin{array}{l}\text { Vehicle } \\
\text { control }\end{array}$ & 0 & 4 & 2 & 0 & 0 & 4 & 2 & $7(6-7)$ \\
\hline $\begin{array}{l}\text { Silymarin } \\
50 \mathrm{mg} / \mathrm{kg}\end{array}$ & 0 & 4 & 2 & 0 & 5 & 1 & 0 & $1.5^{*}(1-6)$ \\
\hline $\begin{array}{l}\text { Lycopene } \\
5 \mathrm{mg} / \mathrm{kg}\end{array}$ & 0 & 3 & 3 & 0 & 2 & 3 & 1 & $6.5(2-7)$ \\
\hline $\begin{array}{l}\text { Lycopene } \\
10 \mathrm{mg} / \mathrm{kg}\end{array}$ & 0 & 4 & 2 & 0 & 0 & 0 & 0 & $1 * *(1-2)$ \\
\hline
\end{tabular}
Dunn's test (versus vehicle control); Scoring system by National Health Services, Maryland, USA, 1979.
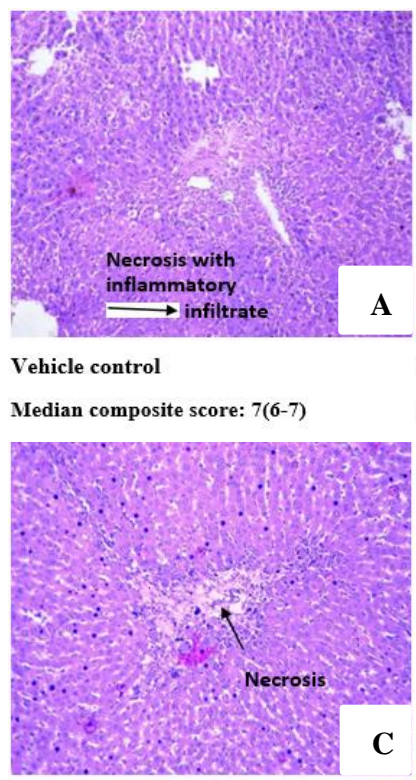

Lycopene $5 \mathrm{mg} / \mathrm{kg}$

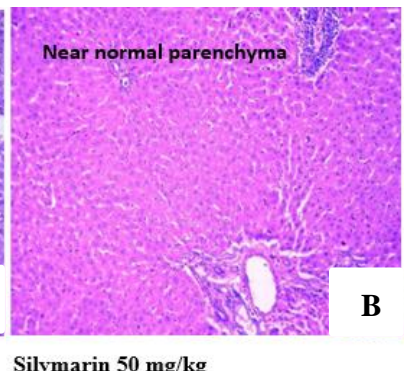

Silymarin $50 \mathrm{mg} / \mathrm{kg}$

Median composite score: $1.5^{*}(1-6)$

Median composite score: $6.5(2-7) \quad$ Median composite score: $1^{* *}(0-2)$

* $\mathrm{p}<0.05$, ** $\mathrm{p}<0.001$ using Kruskal Wallis and post-hoc Dunn's test (versus vehicle control)

(hematoxylin and eosin stain; magnification 10X10)

Figure 2: (A to D) effects of study drugs on histopathology in rat model of anti-tubercular drug induced hepatic damage (Part B).

\section{DISCUSSION}

While standardizing this model, we chose serum bilirubin, AST, ALT, serum albumin and serum cholesterol as biochemical parameters. As there were no changes in serum albumin and serum cholesterol values, 
they were not analyzed in phase II. Alkaline phosphatase levels are not specific for liver damage and show very wide fluctuations in the range. So, it was not included in the biochemical parameter of assessment. Morphological parameters such as liver weight and liver volume were measured to assess changes in liver morphology. Structural alterations the liver due to ongoing insults was confirmed by doing histopathological examination of liver at the end of study.

During standardization of our study, none of the study animals died during the study period. The inducing agents produced significant $(p<0.05)$ elevation in serum bilirubin, AST and ALT levels, compared to the normal control. Histopathological examination showed significant degeneration and necrosis in the groups treated with paracetamol and anti-tubercular drugs (isoniazid + rifampicin). Lycopene has caught the attention of investigators as a potential hepatoprotective due to its antioxidant, anti-inflammatory and antiproliferative properties. It has shown significant protection against radiation induced and halothane induced hepatic damage in rats in previous studies. ${ }^{4,6}$

The antioxidant properties of lycopene may be responsible for the reduced risk of cancer and heart disease in the numerous epidemiological studies. ${ }^{7}$ The antioxidant properties of lycopene to quench singlet oxygen and to capture nitrogen dioxide, thiyl and sulphonyl free radicals, have been extensively evaluated in cell cultures and animal studies.

Liver is the chief target organ of lycopene accumulation in the body. After oral administration, lycopene is rapidly absorbed and gets accumulated in the liver, with a lesser amount going to the spleen. Safety of lycopene has been proved beyond doubt in multiple toxicity studies. No significant toxic effects were observed with lycopene upto $500 \mathrm{mg} / \mathrm{kg}$ body weight when administered for 14 weeks or $1000 \mathrm{mg} / \mathrm{kg}$ body weight for 4 weeks or 2000 $\mathrm{mg} / \mathrm{kg}$ body weight. ${ }^{8}$

Several animal studies have compared the antioxidant properties of lycopene against various chemotherapeutic agents, based on the antioxidant status and lipid peroxidation.

Meydan et al, studied the radioprotective effect of lycopene against liver damage in Sprague Dawley rats. ${ }^{4}$ Lycopene administered orally daily in the dose of $5 \mathrm{mg} / \mathrm{kg}$ body weight showed a significant $(\mathrm{p}<0.05)$ decrease in malondialdehyde, glutathione, glutathione peroxidase, superoxide dismutase levels and decrease in histopathological damage in lycopene treated groups, suggesting that lycopene supplementation significantly reduced radiotherapy induced oxidative liver injury. ${ }^{4}$ The animal study in Wistar rats by Bestas A et al., examined the effects of lycopene and vitamin $\mathrm{E}$ on halothane induced hepatotoxicity. ${ }^{6}$ Halothane induced hepatitis is a common clinical scenario. There was significant reduction in total antioxidant capacity, total oxidant level and sulfhydryl thiol groups ( $\mathrm{SH})$, seen with lycopene and lycopene and vitamin E treated groups. ${ }^{6}$ This was evident in terms of lesser hepatocyte damage on histopathological examination.

A study by Byramoglu et al, has shown that lycopene has a protective effect against ischemia/reperfusion injury on the liver attributable to its antioxidant and antiinflammatory effect. ${ }^{9}$ Sheriff $\mathrm{S}$ et al, studied the effect of lycopene on D-galactosamine/lipopolysaccharide induced hepatitis in rats by analyzing the biochemical parameters and liver marker enzymes and the findings suggest that lycopene is potential agent of hepatoprotection. ${ }^{10}$ In another study, lycopene offered significant protection against $\mathrm{CCl}_{4}$-induced hepatocellular injury; an effect that could be attributed to its antioxidant, antiapoptotic and antifibrotic activities. ${ }^{5}$ Lycopene afforded significant protection against renal damage induced by cisplatin in a study. ${ }^{11}$

There was also cardioprotective effect reported with lycopene in adriamycin induced cardiotoxicity, which is again mediated through reactive intermediates. ${ }^{12}$ Estimation of markers of oxidative damage such as MDA, GSH and SOD could have been done and correlated with the biochemical and histopathological results. However, these investigations were carried out because of limited resources. This is a major limitation of our study. Nevertheless, results of the present study clearly show that lycopene exerts hepatoprotective effect against paracetamol and anti-tubercular drugs (isoniazid + rifampicin) induced hepatic damage in rats. Detailed pharmacokinetic studies of lycopene in the settings of hepatic disease need to be done.

Given the current status of lycopene as a nutraceutical, food-food interactions with lycopene and other nutritional supplements need to be studied. Also lycopene- drug interactions have to be studied in future. Lycopene needs to be evaluated in other models of hepatotoxicity with higher doses given its wide safety margin. Further studies are required to delineate its mechanism of action. In future, lycopene could be a potential hepatoprotective agent for drug induced hepatotoxicity in clinical use, especially in the prevention/treatment of paracetamol and antitubercular drug induced hepatotoxicity. ${ }^{13,14}$

\section{Limitations}

The model of hepatotoxicity induced by anti-tubercular drugs may not actually mimic human hepatotoxicity. Addition of parameters of anti-oxidant activity like liver MDA and GSH could have made the study more robust.

\section{CONCLUSION}

The results of the present study prove that lycopene exerts hepatoprotective effect against paracetamol and anti-tubercular drugs (isoniazid + rifampicin) induced 
hepatic damage in rats. Lycopene needs to be evaluated in other models of hepatotoxicity and further studies are required to delineate its mechanism of action. Lycopene could be a potential hepatoprotective for clinical use in future.

Funding: Funding sources from Diamond Jubilee Society Trust, Seth G. S. Medical College and K. E. M. Hospital, Mumbai, Maharashtra, India

Conflict of interest: None declared

Ethical approval: The study was approved by the Institutional Animal Ethics Committee

\section{REFERENCES}

1. Ostapowicz G, Fontana RJ, Schiodt FV. Results of a prospective study of acute liver failure at 17 tertiary care centers in the US. Annals Internal Medicine. 2002;137(12):947-54.

2. Lewis JH. Drug induced liver disease. Advances in gastroenterology. 2000;84(5):1275-312.

3. An AC, Seth AK, Paul M, Puri P. Risk factors of hepatotoxicity during anti-tubercular treatment. MJAFI. 2000;62:45-9.

4. Meydan D, Gurseli B, Bilgici B, Can B, Ozbek N. Protective effect of lycopene against radiationinduced hepatic toxicity in rats. The Journal of International Medical Research. 2011;39:1239-52.

5. El Sayed E, Fouda E, Mansour A, Elazab A. Protective Effect of Lycopene against Carbon Tetrachloride-Induced Hepatic Damage in Rats. International Journal of Pharma Sciences. 2015;5(1):875-81.

6. Beştaş A, Kahramanoglu M, Erhan OL, Bolat E, Ozercan I, Gürsu F, et al. The role of the antioxidants lycopene and vitamin $\mathrm{E}$ in the prevention of halothane-induced hepatotoxicity. Methods Find Exp Clin Pharmacol. 2008;30(8):627-31.
7. Rao AV, Agarwal S. Role of antioxidant lycopene in cancer and heart disease. J Am Coll Nutr. 2000;19:563-9.

8. Zimmerman HJ. Drug Hepatotoxicity: Spectrum of clinical lesions. In Drug Reactions and the Liver, eds. Davis M, Tredger JM, Williams R, London: Pitman Medical; 1981:35-53.

9. Bayramoglu G, Bayramoglu A, Altunur Y, Uyanoglu M, Colak S. The effects of lycopene on hepatic ischemia/reperfusion injury in rats. Cytotechnology. 2015;67(3):487-91.

10. Sheriff S, Devaki T. Lycopene stabilizes liver function during D- galactosamine/ lipopolysaccharide induced hepatitis in rats. Journal of Taibah University for Science. 2013;7(1):8-16.

11. Atessahin A, Yilmaz S, Karahan I. Effects of lycopene against cisplatin induced nephrotoxicity and oxidative stress in rats. Toxicology. 2005;212:11623.

12. Yelmaz S, Atessahin A, Sahna E. Protective effect of lycopene on adriamycin induced cardiotoxicity and nephrotoxicity. Toxicology. 2006;218:164-71.

13. Larsen A, Polson J, Fontana R, Davern TJ, Lalanj E, Hynan LS, et al. Acetaminophen-induced acute liver failure: results of $\mathrm{U}$ S. Multi-center prospective study. Hepatology. 2005;42:1364-72.

14. Ostapowicz G, Fontana RB, Larson AM. Etiology and outcome of acute liver failure in the USA: preliminary results of a prospective multi-center study. Hepatology. 1999;30(4):221A.

Cite this article as: Joshi SS, Tadavi FM, Manjunatha TA, Kurle DG. Study of evaluation of hepatoprotective potential of lycopene in rat models of paracetamol and antitubercular drugs (isoniazid + rifampicin) induced hepatotoxicity. Int J Basic Clin Pharmacol 2017;6:1585-90. 